\title{
A ATUALIDADE DE MONTAIGNE
}

Márcio Silveira Lemgruber*

Resumo: Este artigo tem por objetivo destacar e discutir ideias apresentadas pelo filósofo francês Michel de Montaigne (1533-1592), em seus Ensaios. Apesar dos séculos que nos separam, a obra de Montaigne tem muito a nos dizer em relação a diversos aspectos como a reflexão sobre si mesmo, a diversidade cultural e suas concepções epistemológicas e educacionais, que soam, ainda hoje, avançadas $e$ originais.

Palavras-chave: Filosofia; Educação; Filosofia da Educação; Montaigne, Ensaios.

Resumen: El artículo tiene como objetivo destacar y discutir ideas presentadas por el filósofo francés Michel de Montaigne (1533-1592) en sus Ensayos. A pesar de los siglos que nos separan, la obra de Montaigne es muy significativa sobre diversos aspectos como la reflexión sobre sí mismo, la diversidad cultural y sus concepciones epistemológicas y educacionales, que suenan, aún hoy, avanzadas y originales.

Palabras claves: Filosofía, Educación, Filosofía de la Educación, Montaigne, Ensayos.

\footnotetext{
* Professor do Programa de Pós-Graduação em Educação da Universidade Estácio de Sá. mslemgruber@gmail.com
}

Dizem que no Brasil as pessoas só morrem de velhice.

Pretendo, aqui, trazer algumas das ideias expostas por Michel de Montaigne em seus Ensaios. Apesar de terem sido escritas há mais de quatro séculos, elas guardam uma instigante atualidade e podem nos ajudar a refletir sobre algumas das principais questões que se nos colocam hoje, inclusive para a filosofia da educação. Ao abordar uma obra tão vasta, é necessário estabelecer recortes. Assim, tenho a intenção de trazer quatro aspectos, a saber: a originalidade de sua escrita; sua crítica à arrogância do conhecimento humano; a ênfase na diversidade cultural; e, por fim, sua concepção de educação.

Posso dizer que meu encontro com Montaigne é recente. Mesmo já tendo um exemplar dos Ensaios há muito tempo, na coleção Os Pensadores, ler um livro de quase mil páginas é uma empreitada que, no ritmo da vida atual, exige uma decisão que 
envolve grande disponibilidade de tempo. Minha vontade de ler Montaigne era, constantemente, renovada em estudos da teoria da argumentação, onde Chaïm Perelman e José Américo Pessanha destacam a importância do renascimento $e$, especificamente, daquele autor como exemplo de exercício filosófico calcado na racionalidade argumentativa. Além disso, compartilhava a intenção de ler Montaigne com um amigo, escritor e crítico literário, que me informou ser ele considerado o patrono dos escritores. Ao buscar essa referência na internet, deparei-me com um traço muito forte de sua atualidade, pois ele é tido, igualmente, como o patrono dos blogueiros. É a partir dessa qualificação que introduzo o primeiro dos pontos que elenquei para abordar aqui: a originalidade de sua escrita. Convém, inicialmente, situar o autor.

\section{O sujeito cindido}

Michel Eyquem de Montaigne foi um francês do século XVI, membro da nobreza, que, em 1568, com a morte do pai, herdou as terras e o castelo de Montaigne. Entretanto, não era afeito às coisas da vida do campo, sua paixão eram as letras. Pouco tempo depois, toma a decisão que mudará radicalmente sua vida: abandona o cargo de magistrado em Bordeaux e passa a escrever sistematicamente. É dessa atividade diária de escrita manifestando sua opinião pessoal sobre qualquer assunto que resolva tratar que vem, nos dias de hoje, a sua fama de precursor dos blogueiros. Tal hábito resultou na obra Ensaios (inicialmente, livros I e II), que editou em 1580 e na qual trabalharia até a morte. Ao fim, compôs 107 ensaios ou capítulos, divididos em três livros, sobre os mais variados temas, desde reflexões éticas ou sobre a morte até a exposição de intimidades corriqueiras como sua doença renal ou preferências culinárias. Porém, não são propriamente os temas que conferem o traço de originalidade aos Ensaios, mas a maneira como os aborda.

O que mais nos chama a atenção é o caráter de invenção dos Ensaios. Sua escrita é fluida como uma conversa, realizando relações e digressões ao seu bel prazer. Leitor, na infância, das Metamorfoses, de Ovídio, e, mais tarde, dos Opúsculos e 
Vidas, de Plutarco, herda desses autores o estilo fragmentário, ágil, que encantará o público por tantos séculos.

É difícil classificar o que ele faz: É filosofia? É literatura? São testemunhos, diários, confissões? Talvez um pouco disso tudo. O certo é que Montaigne se expõe como dificilmente um filósofo ou escritor já houvera feito. Escancara sua intimidade, expondo desde as dificuldades na vida conjugal, o declínio de sua vida sexual, até manias e defeitos os mais comuns como a inveja dos vizinhos, ou sua tão proclamada preguiça. Mas é exatamente com isso que ele nos cativa, pois, no que ele escreve de si, identificamos nossas próprias limitações e dificuldades. Temos a sensação de estar em linha direta com alguém que, apesar da imensa distância no tempo, parece estar se dirigindo particularmente a cada um de nós.

Montaigne não inaugurou o gênero de escrita pessoal, tipo Confissões, Memórias, Diários, ou Ensaios. Certamente, conhecia, a respeito, bons exemplos: gregos, romanos, além de franceses contemporâneos e seus vizinhos europeus. Mas o revolu- cionou ao assumir-se como sujeito cindido: "somos, não sei como, dois seres em um só, o que faz que, em uma mesma coisa, acreditemos e não acreditemos, não podendo desfazernos do que condenamos" (MONTAIGNE, 1996, vol. II, pág. 13). Tal formulação ou, quando diz que "nunca estamos em nós; estamos sempre além" (Idem, vol. I, pág. 39), ainda hoje, são impactantes.

Obviamente, não podemos idealizar o caráter precursor de Montaigne, sustentando, por exemplo, que ele tenha proposto o conceito de inconsciente, mais de trezentos anos antes de Sigmund Freud. Mas, ainda assim, não resisto a registrar a semelhança de expressões com que esses pensadores apontaram as limitações do ser humano. Diz-nos Freud, em suas Conferências Introdutórias à Psicanálise:

Mas a megalomania humana terá sofrido seu terceiro golpe, o mais violento, a partir da pesquisa psicológica da época atual, que procura provar ao ego que ele não é senhor nem mesmo em sua própria casa, devendo, porém contentar-se com escassas informações acerca do que acontece inconscientemente em sua mente. (FREUD, s.d., vol.XVI, pág. 336). 
Já Montaigne fustigara: "Será possível imaginar algo mais ridículo do que essa miserável criatura, que nem sequer é dona de si mesma, que está exposta a todos os desastres e se proclama senhora do universo?" (MONTAIGNE, 1996, vol. I, pág. 379).

Do mesmo modo que ele desconfiava da capacidade de a humanidade atingir um conhecimento definitivo sobre o mundo, ao voltar-se para si mesmo, cada vez mais, ao longo dos anos de elaboração dos Ensaios, percebe as limitações de sua própria razão em comandar seus pensamentos e atos, pois "não me encontre onde me procuro" (Idem, vol. I, pág. 60). Ou, ainda, "Com o hábito e o tempo, familiarizamo-nos com tudo o que é estranho; apesar disso, quanto mais me analiso e conheço, tanto mais minha deformidade me espanta e menos eu me compreendo." (Idem, vol. II, pág. 326).

Seu campo de reflexão filosófica é, então, o estudo de si mesmo. Não por se julgar especial, por uma promessa de escrita sincera, ou por haver encontrado um método de pensar sem se enganar. Ao contrário, toma- se como objeto por se ver como uma pessoa comum. Montaigne sabe que seu discurso é falho, não por ser Montaigne, mas, tão somente, por ser humano. Para ele, falar de um homem - no caso, de si mesmo - é falar do Homem. "A vida de César não nos oferece mais exemplos do que a nossa, porque tanto a de um imperador quanto a de um homem vulgar são vidas humanas e sujeitas a todos os acidentes humanos". (Idem, vol. II, pág. 362)

Escrever sobre si mesmo, apresentar o processo como se chegou a determinadas conclusões é, desde muito, uma estratégia argumentativa bastante utilizada. Realmente, é de se supor a sinceridade do discurso de quem, por exemplo, invoca Deus para garantir que só dirá a verdade. Isso confere força aos argumentos. É a deliberação consigo mesmo (PERELMAN e OLBRECHTS-TYTECA, 1996) como uma instância onde, pela boa intenção dos propósitos, promete-se blindar a falsidade.

Nos Ensaios, porém, Montaigne, em seu acordo prévio com o leitor, não promete um método para pensar sem erro, um sistema filosófico que dê 
conta da realidade. Não escreve para explicar o mundo, para revelar o que está "por trás" das coisas. O alvo de suas meditações é o que está "dentro" da gente: "Os males da alma, ao contrário, tornam-se menos visíveis com a agravação; o mais doente é quem menos os sente. Eis por que é preciso não raro examiná-los de perto, arrancando-os sem dó do fundo do coração". (Idem, vol. II, pág. 187)

\section{Filosofia para a vida}

Quanto a sua filiação filosófica, Montaigne é apontado como um dos principais representantes do humanismo renascentista, leitor apaixonado de Sêneca e Plutarco. Sua atração pelas escolas pragmáticas da antiguidade - estoicismo, epicurismo e o ceticismo - vinha do lugar elevado na hierarquia dos valores que elas conferiam à atenção constante sobre a própria vida, através da ataraxia, isto é, a imperturbabilidade enquanto diminuição da ansiedade:

A grandeza da alma consiste menos em se elevar e avançar do que em se ordenar e se circunscrever. Grande é tudo o que é suficiente; e há mais elevação em amar as coisas comuns do que as eminentes. Nada é tão legítimo e belo como desempenhar o papel de homem em todos os seus aspectos. Não há ciência mais árdua do que a de saber viver naturalmente; e a mais terrível das moléstias é o desprezo pela vida. (Idem, vol. II, pág. 392)

Montaigne distingue territórios que suportam diferentes concepções de racionalidade. Entende que não se pode construir uma ética more geometrico, que os conhecimentos dessa ordem não resolvem os dilemas da conduta humana. A vida pode ser tudo, menos exatidão. Nela, a lógica do falso ou verdadeiro não impera. Ela não tem gabarito, ao contrário dos sistemas formalizados ou das questões passíveis de cálculos: "a virtude que as coisas deste mundo exigem é uma virtude flexível, capaz de se adaptar à fraqueza humana; não é pura nem simples; não é reta, constante, imaculada" (Idem, 1996, vol. II, pág. 298).

Conta que se tornou filósofo por acaso, sem um projeto predeterminado:

Minhas ideias são o que as fez a natureza. Para formá-las procurei não seguir nenhuma regra; $e$ no entanto, por fracas que sejam, quando as quis exprimir $e$ publicar nas melhores condições possíveis, achei de meu dever apoiá-las em raciocínios e exemplos, e maravilhei-me com perceber a que ponto se amolNúmero 21: novembro/2013-abril/2014 
dam a inúmeros raciocínios filosóficos. A que doutrina se ligam? Só o soube depois de as expor e julgar do resultado; pertenço a uma nova espécie, sou um filósofo que se tornou filósofo por acaso e sem premeditação. (Idem, vol. I, pág. 457).

O capítulo em que mais desen-

volve suas ideias filosóficas é Apologia de Raymond Sebond. Trata-se de um capítulo atípico. Seu tamanho, com mais de 100 páginas, contrasta com os demais, em geral, curtos. Foi decorrência de um trabalho feito de encomenda para seu pai, a tradução da Teologia Natural ou Livro das Criaturas, de Raymond Sebond. Ao escrever sobre essa obra, na verdade, faz uma estranha apologia, digna da expressão "com amigos assim, você não precisa de inimigos". Isso porque, efetivamente, o que faz é um contunde ataque ao que Sebond se pretende, a saber, à possibilidade de se fundamentar uma teologia na razão. Esse é o pretexto para Montaigne exercitar seu tema preferido: ironizar a arrogância do conhecimento humano.

Que me explique pelo raciocínio em que consiste a grande superioridade que pretende ter sobre as demais criaturas. Quem o autoriza a pensar que o movimento admirável da abóboda celeste, a luz eterna dessas tochas girando majestosamente sobre sua cabeça, as flutuações como- ventes do mar de horizontes infinitos, foram criados e continuem a existir unicamente para sua comodidade e serviço? (Idem, vol. I, pág. 379)

Por sinal, esse foi o ponto que levou os Ensaios ao Índex dos livros proibidos de 1662 até 1854: a denúncia do influente bispo Boussuet de que o livro de Montaigne, ao aproximar o homem dos outros animais, não o destacava como criação especial de Deus.

Chega a surpreender a atualidade de sua concepção epistemológica, a clareza com que percebia as limitações das teorias científicas e filosóficas de maior prestígio, o caráter de transitoriedade de seus modelos, o recurso a "licenças poéticas" para encobrir suas limitações:

Duvido que Epicuro, Platão e Pitágoras tenham acreditado seriamente em suas teorias dos átomos, das ideias e dos números; eram demasiado sábios $e$ prudentes para crerem em coisas tão pouco assentadas e tão discutíveis. O que na realidade pode assegurar-se é que, dada a obscuridade das coisas do mundo, cada um desses grandes homens procurou encontrar uma imagem luminosa delas. Seus espíritos acharam explicações que tinham pelo menos uma certa verossimilhança $e$ que, embora não averiguadamente verdadeiras, podiam ser sustentadas contra as ideias contrárias: "esses sistemas são 
ficções do gênio de cada filósofo e não o resultado de suas descobertas". (Sêneca). (Idem, vol. I, pág. 428)

Critica os sistemas filosóficos que se assentam em verdades primeiras, fundamentais, para depois construírem o edifício à vontade sobre esses alicerces sem incidir em contradição alguma. "Com esse processo nossa razão marcha com segurança $e$ nós discorremos sem necessidade de investigações mais aprofundadas" (Idem, vol. I, pág. 452)

Desconfia da perenidade de qualquer saber. Indaga que "carta de recomendação" trazem os ensinamentos de Aristóteles, para não serem superados por outros? Que privilégio especial lhes garante que as nossas invenções os preservarão eternamente?

Montaigne viveu em uma época de grande mudança na ideia que se fazia quanto ao tamanho do mundo. Tanto da Terra em relação ao universo, quanto do próprio planeta. A astronomia passava por uma revolução, com o movimento das esferas celestes do geocentrismo de Ptolomeu sendo superado pela explicação a partir da rotação da Terra, no heliocentrismo de Copérnico. Montaigne saúda o novo conhecimento, mas se recusa a considerar que o homem, enfim, decifrara o cosmos. "Quem sabe daqui a mil anos outro sistema não os destruirá a ambos?" (Idem, vol. I, pág. 477) Também esta será a sua postura em relação ao descobrimento do Novo Mundo, como etapa final do conhecimento das fronteiras do planeta em que vivemos:

E eis que nesse século se descobre um continente de enorme extensão, não uma ilha, mas uma região quase igual em superfície às que conhecíamos. Os geógrafos de nosso tempo não deixam de afirmar que agora tudo é conhecido. Pergunto então se, visto que Ptolomeu se enganou outrora acerca do que constituía o ponto de partida de seu raciocínio, não seria tolice acreditar hoje resolutamente nas ideias de seus sucessores, e se não é provável que esse grande corpo denominado "mundo" seja bem diferente do que julgamos? (Idem,vol.I, pág. 478)

\section{Diversidade cultural}

Apesar de sua inquestionável fé católica e de ter vivido no período das guerras religiosas em França, jamais sucumbiu à intolerância. Isto porque compreendia sua opção religiosa determinada não por uma verdade transcendental, mas, sobretudo, pelas contingências culturais: "outras regi- 
ões, outras influências, promessas $e$ ameaças poderiam igualmente impornos outras crenças. Somos cristãos como somos perigordinos ou alemães." (Idem, vol. I, pág. 375). É significativo que, ao longo de mil páginas, não haja qualquer alusão a Jesus Cristo. Mesmo quando vai tratar de exemplos de atitude diante da morte, recorre a Catão ou Sócrates, mas omite a crucificação. Transparece que sua verdadeira religião é o legado humanista greco-romano, em especial as tradições do estoicismo, do epicurismo e do ceticismo.

Já no século XVIII, a descoberta de mais um Novo Mundo, ao sul do Pacífico, contribuiu para que o tema dos indígenas voltasse à moda. Intelectuais como Diderot e Rousseau buscaram inspiração para a idealização do "bom selvagem" no ensaio Os canibais, onde Montaigne apresenta sua visão simpática aos costumes primitivos e estrangeiros. "Nada vejo de bárbaro ou selvagem no que dizem daqueles povos; e, na verdade, cada qual considera bárbaro o que não se pratica em sua terra." (Idem, vol. 1, pág. 195)
Montaigne se interessou sobremaneira pelos relatos sobre o Novo Mundo. Teve em sua propriedade um empregado que vivera uns dez anos na França Antártica, fundada pelo almirante Villegaignon, no Brasil. Gostava de conversar sobre os índios com esse homem que tinha a seu serviço, pois era simples e grosseiro de espírito, o que dava mais valor a seu testemunho. Assim como a propósito dos historiadores, lamentava as pessoas refinadas que acham que devem valorizar seus relatos com comentários e acabam por deformar e ampliar o que viram. Defendia que a informação objetiva nós a temos das pessoas muito escrupulosas ou muito simples. E assim era o seu informante, que lhe apresentou marinheiros e comerciantes que conhecera na viagem.

Dedicava muito tempo à leitura das obras sobre os povos recémdescobertos. Gostava sobretudo da Histoire d'um Voyage fait em terre Du Brésil (1578), de Jean de Léry, cronista protestante que descrevia a sociedade tupinambá com simpatia; e da Brevisima relación de la destruccion de las Indias, de Bartolomé de Las 
Casas, que defendia a causa da humanidade dos silvícolas.

Montaigne valorizava as diversas culturas, na medida em que conseguia descentrar o seu olhar, desnaturalizar os próprios costumes, percebendo-os como construções culturais. Isso não era só uma postura teórica, mas uma curiosidade que levava para o dia a dia: "Em lugar de pão, comem uma substância branca parecida com o coentro cozido. Experimentei, é doce e algo insosso." (Idem, vol. I, pág. 197)

Um episódio que ficou famoso em Os Canibais é quando narra o encontro, em Rouen, na corte do rei Carlos IX, com três índios tupinambás trazidos do Brasil (lastima que se tenham deixado tentar pela novidade $e$ abandonado seu clima suave). Vendo-os como um espelho, o que mais chamou a atenção de Montaigne foi a percepção dos índios quanto à desigualdade na sociedade francesa:

observaram que há entre nós gente bem alimentada, gozando as comodidades da vida, enquanto metades de homens emagrecidos, esfaimados, miseráveis, mendigam às portas dos outros (em sua linguagem metafórica a tais infelizes chamam "metades"); e acham extraordinário que essas metades de ho- mens suportem tanta injustiça sem se revoltarem $e$ incendiarem as casas dos demais. (Idem, vol. I, pág. 203)

\section{Educação para a vida}

Como último aspecto a ser abordado, após um breve resumo de sua formação, apresento algumas de suas reflexões sobre educação, considerada por ele a maior e mais importante dificuldade da ciência humana.

Mesmo sendo um homem pouco culto, Pierre de Montaigne investiu original e ousadamente na educação do filho. Em vez de mandar vir uma ama de leite ao castelo, enviou seu filho para uma aldeia pobre. Montaigne relata que se a intenção do seu pai era aproximá-lo do povo, foi bem sucedida, pois sempre se ocupou com prazer dos pequenos.

Mais ousada ainda foi a iniciativa seguinte, agora já em sua casa. Logo que desmamou, antes que destravasse a língua, foi confiado a um preceptor alemão que ignorava completamente o francês. Ele e mais dois ajudantes, só se dirigiam ao pequeno Michel em latim. "Excelente foi o resultado. Sem método, sem livros, sem gramática, sem regras, sem chicote, sem lágrimas, aprendera um latim tão 
puro quanto o de meu professor, porquanto nenhuma noção de uma outra língua o podia perturbar." (Idem, vol. I, pág. 170) Assim, ele conheceu o Capitólio antes do Louvre, o Tibre antes do Sena.

Aos seis anos foi para o Colégio de Guyenne, em Bordeaux, um dos melhores, então, em França, de onde saiu aos treze, sem levar maiores saudades. Entretanto, reconhece que ali conheceu o prazer da leitura. Sua cartilha foram as fábulas das Metamorfoses de Ovídio, o livro mais fácil que conhecia e o mais adequado pelo assunto à sua idade. Depois, devorou de fio a pavio a Eneida, Terêncio e Plauto, e as comédias italianas, sempre buscando uma leitura agradável. Nesse aspecto, elogia alguns professores: "Se tivessem tido a mania de mo impedir, creio que só houvera trazido do colégio ódio aos livros, como acontece com quase toda a nossa nobreza." (Idem, vol. I, pág. 172) É inevitável pensar que, ainda hoje, tantas escolas ou faculdades fracassam na sedução para a literatura, tomando-a como exercício escolar.

$\mathrm{Na}$ verdade, a filosofia do Collège era relativamente aberta, tan- to que, em 1547, o diretor, um português progressista chamado André Gouvéa, foi demitido pelos conservadores. Montaigne escreveria que saiu de lá sem qualquer fruto que lhe fosse de utilidade, mas foi ali que desenvolveu uma capacidade de expressão $e$ argumentação de que se valeria por toda a vida.

Mesmo não chegando a sistematizar suas concepções educacionais como Rousseau, que o fez no romance pedagógico Emilio ou da Educação, Montaigne é apontado nos livros de História da Educação, como um crítico mordaz das práticas pedagógicas de memorização e da disciplina rígida e violenta que imperavam em seu tempo. Além de observações esparsas ao longo de sua obra, dedicou dois capítulos especificamente sobre a educação: Pedantismo e Da educação das crianças.

Para trazer aqui algumas destas ideias vamos partir de uma história com que ilustra um aspecto ao qual dá grande ênfase: o aluno não deve receber um saber pronto para tão somente memorizar, mas que seja instigado a buscar o conhecimento e realizar uma produção própria. 
Conta-nos (Idem, vol. I pág. 427) que Demócrito, tendo comido figos que sabiam a mel, pôs-se imediatamente a procurar, na memória, de que provinha tão inesperada doçura. A fim de verificá-lo, já se levantava para ir examinar o lugar onde os frutos haviam sido colhidos, quando sua criada, que percebera o motivo da inquietação, lhe disse rindo que não se preocupasse mais, pois fora ela que os colocara em um recipiente em que havia mel. Ele se irritou por lhe sonegarem a oportunidade de pesquisas e de exercitar sua curiosidade: "não é um prazer que me dás", observou, "mas nem por isso deixarei de verificar como isso ocorreu, tal qual tivesse resultado de um efeito da natureza”. E naturalmente houvera encontrado uma razão com aparência de verdadeira, a fim de explicar algo que só existia em seu espírito. E conclui que essa narrativa acerca de um grande filósofo exemplifica bem a paixão pelo estudo, capaz de nos induzir ao desespero por termos alcançado o conhecimento das coisas que procurávamos conhecer.

É também esse o teor da analogia, recurso argumentativo dos mais usados nos Ensaios, com que critica os conteúdos escolares lançados goela abaixo nos alunos: "Assim como os pássaros vão às vezes em busca de grão que trazem aos filhotes sem sequer sentir-lhe o gosto, vão nossos mestres pilhando a ciência nos livros e a trazendo na ponta da língua tão somente para vomitá-la e lançá-la ao vento." (Idem, vol. I, pág. 140) Chama-os de "Lettreferus" (ferido pelas letras), isto é, indivíduos que as letras atordoaram à maneira de uma martelada.

Em contrapartida, é uma concepção autoral de conhecimento que o estimula a advogar o ensino da filosofia para as crianças: "Visto que a filosofia é a ciência que nos ensina a viver e que a infância como as outras idades dela pode tirar ensinamentos, por que motivo não lha comunicaremos?" (Idem, vol. I, pág. 162) Desse modo, as crianças deveriam ser habituadas às dúvidas e não às afirmações. É melhor que se pareçam aprendizes aos sessenta anos do que doutores aos dez, julga o ensaísta, ele próprio perto daquela idade.

Em outra analogia, aproxima abelhas e alunos, pois, assim como 
aquelas passam por flores de toda espécie, mas fazem o mel que é unicamente seu, os alunos devem trabalhar nos elementos tirados de outrem para com eles tecer um conhecimento seu, isto é, forjar a sua inteligência.

Montaigne levou à prática seu ideal pedagógico de produzir um conhecimento autoral, de produzir seu próprio mel. E como foi autoral em sua escrita. Sua verve argumentativa não se deixou conformar ao modelo retórico imperante. Desprezava o formalismo, a artificialidade das escolas de retórica. Sua escrita foi ganhando vida própria ao longo de quase vinte anos. Seu estilo foi se tornando cada vez mais pessoal, literário. Transparece que há uma pessoa que escreve e ela é o personagem principal. Montaigne transita por centenas de pensadores, mas a sua palavra é a que aparece. "Não me inspiro nas citações; valho-me delas para corroborar o que digo e que não sei tão bem expressar" (Idem, vol. II, pág. 349)

Suas ideias pedagógicas visam dois grandes alvos. O primeiro deles é a disciplina rígida, por meio de castigos físicos:
A disciplina rigorosa da maior parte de nossos colégios sempre me desagradou. São verdadeiras prisões para cativeiro da juventude... Ide ver esses colégios nas horas de estudo: só ouvireis gritos de crianças martirizadas $e$ de mestres furibundos. Linda maneira de acrodar o interesse pelas lições nessas almas tenras e tímidas, essa de ministrá-las carrancudo e de chicote nas mãos! Que método iníquo e pernicioso! Como seriam melhores as classes se juncadas de flores e folhas e não de varas sanguinolentas! (Idem,vol. I, pág. 164)

O segundo é o ideal de educação calcado na memorização, a ideia de que saber é ter muita informação armazenada na cabeça, o que levava à decoreba de trechos enormes de livros, mesmo que não compreendidos. São os "cabeça de pote", como ridicularizou.

Em oposição a esta triste ciência puramente livresca, preconiza que se criem situações onde as discípulos possam fazer escolhas, defender pontos de vista, em suma, desenvolver um saber próprio. No sentido de dar voz aos estudantes, quer que o ensino, além das lições de leituras, se faça por conversas. Lembra que Sócrates obrigava os discípulos a falarem primeiro e somente depois falava ele próprio. Percebe que um dos pontos 
mais importantes e difíceis da arte da didática é o adulto saber conectar-se com o espírito infantil e dele retirar seus saberes próprios, intuindo a relevância que será conferida, séculos depois, aos saberes prévios dos alunos. Sobre o ensino da história, outra de suas paixões intelectuais, adverte:

Mas que o guia desse menino se lembre do objetivo de sua missão e que procure gravar menos no seu discípulo a data da destruição de Cartago que os costumes de Aníbal ou Cipião. Que lhe ensine a apreciar os fatos mais do que os registrar. Uns estudam a história decorando, outros como um filósofo que analisa. (Idem, vol. I, pág. 156)

Dava grande valor, na formação do estudante, aos exercícios físicos $e$ às artes, tais como: corrida, luta, música, dança, caça, equitação, esgrima, visto que não é uma alma somente que se educa, nem um corpo, é um homem: cabe não separar as duas parcelas do todo.

Enfim, Montaigne trouxe para a educação a marca de um mundo em expansão, assombrado com as novidades encontradas em continentes distantes (Idem, vol. I, pág. 158): "Este mundo tão grande é o espelho em que devemos nos mirar para nos conhecermos de maneira exata. Em suma, quero que seja esse o livro de nosso aluno. A infinidade de costumes, seitas, juízos, opiniões e leis ensina-nos a apreciar sadiamente os nossos, a reconhecer suas imperfeições e fraquezas naturais, o que já não é pouco."

\section{Conclusão}

À guisa de conclusão, retomo, sistematizando, traços que considero marcantes da atualidade do filósofo francês. Com sua escrita fluida e assistemática, assumindo-se como sujeito de um conhecimento ambíguo, Montaigne leva essa postura pessoal para sua concepção epistemológica, marcadamente histórica e setorial. Pelo que lemos e trouxemos dos Ensaios, percebemos sua influência na concepção proposta, no século $\mathrm{XX}$, por Bachelard de uma filosofia regressiva, no sentido de que se volta permanentemente sobre seus fundamentos. Não há verdades primeiras, mas primeiros erros; a filosofia, em consonância com a ciência, passa a ser também a reforma de uma ilusão, pois as intuições primeiras são sempre intuições a retificar.

Número 21: novembro/2013-abril/2014 
Na época de Montaigne, a humanidade iniciava a saída de um mundo fechado. Como citamos aqui, ele compreendeu a radicalidade da nova teoria de Copérnico, mas atacou fortemente a pretensão de se haver chagado ao modelo definitivo de universo. Recorro a Umberto Eco (2013), quando afirma que o heliocentrismo levou o universo do saber a se esforçar por imitar a forma do universo planetário. Mas, suspeito que, em Montaigne, se deu o inverso: sua concepção aberta do saber é que o levou a apostar em uma concepção aberta do cosmo.

Assim, vejo sua atualidade quando leio o astrofísico Marcelo Gleiser (2010) sustentar que o universo será sempre uma construção humana, "pois ao aprimorarmos os nossos instrumentos e, com ele, aprendermos mais sobre o mundo, aumentamos também a nossa ignorância: quanto mais longe enxergamos, mais existe por enxergar" (p. 147). Penso que o filósofo francês sentiria afinidade com as metáforas fundantes epistemológicas que prevalecem hoje: rede, teia, rizoma, labirinto aberto, etc.
Quanto à diversidade cultural, podemos dizer que Montaigne é atualíssimo. Se há algo de que não pode ser acusado, como vimos, é de naturalizar o cultural. Seu legado é um exemplo de não aceitação da discriminação e da intolerância. Basta-nos lembrar da imensa coragem que teve em assumir uma atitude de independência e denunciar, no auge dos banhos de sangue das guerras religiosas em França, os massacres de seus partidários - os católicos - contra os huguenotes. Escreve com todas as letras que aqueles eram muito mais intransigentes e violentos do que os protestantes. Apesar de não colocar em dúvida a sua filiação católica, tem-na como subordinada ao contexto cultural. Com isso, assume uma postura pluralista, difícil de imaginar em seu tempo, de achar que os costumes $e$ crenças dos outros são tão legítimos como os seus. Em nome desse ideal, escreve um libelo contra o genocídio que os espanhóis - para ele, os verdadeiros bárbaros - praticavam contra os astecas, em nome de Deus. Como uma mensagem lançada dentro de uma garrafa no mar do tempo, chega a nós uma secular denúncia da intole- 
rância religiosa (para focar somente neste aspecto) que, ainda hoje, faz milhões de vítimas pelo mundo. Para nós, educadores, essa mensagem, que emana da torre de seu castelo e atravessa os séculos, reforça a disposição na luta por uma escola pública laica.

Finalmente, quanto à atualidade de suas ideias pedagógicas, busquei levantar índices da influência que exerce entre nós.

Pude constatar que três dos livros sobre a história do pensamento pedagógico de autores nacionais dos mais utilizadas em cursos de formação de professores (ARANHA, 2011; GADOTI, 2011; PILETTI e PILETTI, 2006) destacam a contribuição montaigniana, enfatizando sua crítica à memorização, defendendo uma educação voltada para a vida. Em especial Gadoti, que reproduz um longo texto do ensaio Da educação das crianças e propõe a elaboração de uma dissertação sobre suas concepções educacionais. Por sua vez, Maria Lucia Aranha apresenta um trecho do capítulo Pedantismo e, a partir dele, também propõe problematizações.
Penso, a seguir, na afinidade de algumas das proposições de Montaigne com o ideário do mais influente educador brasileiro: Paulo Freire. Seu livro Pedagogia da autonomia, lançado em 1996, é um recordista, com mais de um milhão de exemplares vendidos. Se acrescentarmos as cópias xerocadas pelos alunos em faculdades e cursos de magistério, teremos um número significativamente maior. Mas, não se trata somente de influência quantitativa. Paulo Freire é reconhecido como a principal referência do pensamento pedagógico progressista, no Brasil.

A tese principal de Pedagogia da autonomia no sentido de que "ensinar não é transferir conhecimento, mas criar as possibilidades para a sua produção ou a sua construção" (FREIRE, 1999, p. 25), guarda forte sintonia com a crítica de Montaigne às práticas pedagógicas calcadas na memorização, ironizando os nelas envolvidos com as alcunhas de "papagaios", "cabeças de pote", "lettreferus".

Percebo, igualmente, sintonia entre eles no que diz respeito à defesa de uma postura pluralista. Como já 
citamos a posição do filósofo francês, destaco, a seguir, um trecho que sintetiza a opinião do educador brasileiro:

Quem observa o faz de um determinado ponto de vista, o que não situa o observador em erro. $\mathrm{O}$ erro na verdade não é ter um certo ponto de vista, mas absolutizá-lo e desconhecer que, mesmo do acerto do seu ponto de vista é possível que a razão nem sempre esteja com ele. (FREIRE, 1999, p. 15/16)

Sabemos que um dos aspectos mais caros à pedagogia freiriana é seu apreço ao saber do educando. Talvez seja esse o traço mais marcante de toda uma linhagem de críticas ao artificialismo e descontextualização das chamadas pedagogias da transmissão. A valorização dos saberes prévios dos educandos, característica do ideário educacional de Paulo Freire, dos construtivismos, do escolanovismo, tem raízes seculares, remontando a Rousseau, mas, antes ainda, a Michel de Montaigne com sua filosofia $e$ educação para a vida.

\section{Referências}

ARANHA, Maria Lucia de Arruda. História da Educação e da Pedagogia - Geral e Brasil. Ed. Moderna, $3^{\text {a }}$. Ed. Revista e ampliada, 2011.

BACHELARD, Gaston. O novo espírito científico. Lisboa: Edições 70, 1986.

BAKEWELL, Sarah. Como Viver ou Uma biografia de Montaigne em uma pergunta e vinte tentativas de resposta. Rio de Janeiro: Objetiva, 2012.

CHATELET, François. Uma história da razão. Rio de Janeiro: Jorge Zahar. 2004.

CHAUÍ, Marilena de Souza. Vida e Obra. In. MONTAIGNE Col.: Os Pensadores, São Paulo: Editora Nova Cultural, 1996.

DESCARTES, René. Meditações. Col.: Os Pensadores. São Paulo: Editora Nova Cultural, 1996.

ECO, Umberto. Da árvore ao labirinto. Rio de Janeiro: Record, 2013.

FREIRE, Paulo. Pedagogia da autonomia: saberes necessários à prática educativa . São Paulo, Paz e Terra, 1999.

FREUD, Sigmund. Conferências Introdutórias sobre Psicanálise. Edição standard brasileira das obras psicológicas completas - vols. XV e XVI, Rio de Janeiro, Imago, s.d.

GADOTTI, Moacir. História das Ideias Pedagógicas. SP: Ática, 1999. 319 págs. $8^{\text {a }}$. edição em 2011. 
GLEISER, Marcelo. Criação imperfeita. Rio de Janeiro: Record, 2010.

LEMGRUBER, Márcio e OLIVEIRA, Renato José de. "Argumentação e Educação: da ágora às nuvens". In. LEMGRUBER, Márcio e OLIVEIRA, Renato José de. (Orgs.) Teoria da Argumentação e Educação. Juiz de Fora: Ed. UFJF, 2011.

MONTAIGNE, Michel. - Ensaios. Vol. 1 e 2. Col.: Os Pensadores. Tradução de Sérgio Milliet. São Paulo: Editora Nova Cultural, 1996.

PERELMAN, Chaïm e OLBRECHTS-TYTECA, Lucie. Tratado da Argumentação a nova retórica. São Paulo, ed. Martins Fontes, 1996. Trad. de Maria Ermantina Galvão G. Pereira.

PILETTI, Nelson e PILETTI, Claudino. História da Educação. SP: Ática, 2006.

ROUSSEAU Emilio ou da Educação. Tradução de Sérgio Milliet. São Paulo: Difusão Européia do Livro, 1968.

Recebido em 10/01/2013

Aprovado em 19/08/2013 